\title{
STUDIES ON THE CIRCULATING INSULIN INHIBITOR FOUND IN SOME DIABETIC PATIENTS EXHIBITING CHRONIC INSULIN RESISTANCE
}

\author{
By JAMES B. FIELD with the technical assistance of MINNIE L. WOODSON
}

(From the Clinical Endocrinology Branch, National Institute of Arthritis and Metabolic Diseases, National Institutes of Health, Bethesda, Md.)

(Submitted for publication September 15, 1958; accepted November 25, 1958)

Chronic insulin resistance in the diabetic patient has been arbitrarily defined as existing when the daily requirement for insulin exceeds 200 units in the absence of complicating infection or ketoacidosis (1). The general problem of insulin resistance has been the subject of several review articles (1-3). Glen and Eaton first demonstrated that serum obtained from an insulinresistant diabetic patient protected rabbits from insulin-induced hypoglycemia (4). Subsequently, the studies of Lowell (5) and Lerman (6) suggested the probable antibody nature of this humoral insulin antagonist. Marsh and Haugaard detected an insulin inhibitor in the sera of four diabetic patients requiring at least 300 units of insulin per day (7). In their experiments the ability of insulin to augment glycogen deposition by the isolated rat hemidiaphragm was utilized as the test system. The serum factor was effective only if it, insulin and the hemidiaphragm were in contact simultaneously. More recently there have been several reported cases of chronic insulin resistance in which the insulin antagonist was localized in the $\gamma$-globulins and presumed to be an antibody (8-13). Colwell and Weiger (13), in an extensive study of such a patient, noted a correlation between the titer of the insulin antagonist and the serum $\gamma$-globulin levels.

Berson and co-workers have demonstrated the presence of an insulin binding protein in the sera of diabetic patients who have received exogenous insulin for at least three months (14). Electrophoretically this protein migrated with the fastest moving $\gamma$-globulins and had many characteristics of an insulin antibody. Similar binding of insulin was not observed in the sera of diabetic patients who had never received insulin treatment, but was found in nondiabetic psychiatric patients who had been given insulin shock therapy. Furthermore, the rate of disappearance of insulin- $\mathrm{I}^{131}$ injected intravenously was found to be decreased in some diabetic patients $(14,15)$. Berson and associates observed that patients receiving exogenous insulin were the ones who demonstrated the decreased rate of disappearance (14). Although the binding of insulin to rat hemidiaphragm was diminished in the presence of such sera, no definite correlation existed between the insulin requirement of a patient and the amount of this insulin binding protein (15). However, increased insulin binding by plasma in cases of chronic insulin resistance has been reported previously $(16,17)$.

Recently adrenocorticotropin (ACTH) and adrenal steroids have been used in the treatment of chronic insulin resistance with variable results $(10,12,18-20)$. Howard (18) successfully treated one case whose serum contained an insulin antagonist (7). At a time when the insulin resistance was no longer apparent clinically, antagonist could still be detected in the serum by the rat hemidiaphragm assay, although later it was no longer demonstrable.

Previously we have demonstrated a circulating insulin antagonist associated with diabetic acidosis $(21,22)$ which is quite distinct from the humoral insulin antagonist demonstrable in some chronically insulin-resistant diabetic patients not in acidosis. The present paper summarizes work which has been done concerning the insulin inhibitor occurring in chronic insulin resistance.

\section{METHODS AND MATERIALS}

The method for assaying insulin antagonism in the rat hemidiaphragm was the same as reported previously (21). In these studies the effect of 0.2 unit of insulin on the glycogen deposition by the rat hemidiaphragm in the presence of $1 \mathrm{ml}$. of serum was measured. The insulin effect using normal serum was $5.35 \mu \mathrm{M}$ glycogen (glucose equivalents) per $\mathrm{Gm}$. of tissue.

Insulin antagonist was also detected by the ability of 
the test serum to protect fasted mice from insulin-induced hypoglycemic death. Albino mice of both sexes weighing 14 to $16 \mathrm{Gm}$. were used. Sixteen hours prior to an assay, the mice were placed in a constant temperature warm room $\left(37^{\circ}\right.$ C. $)$ and given water ad libitum, but no food. At the beginning of an assay, water was withdrawn and each mouse was injected intraperitoneally with $1 \mathrm{ml}$. of serum containing 0.07 unit of insulin and then observed for the following four hours. At least six mice were injected with each serum sample and appropriate controls were included using $1 \mathrm{ml}$. of normal serum and $1 \mathrm{ml}$. of normal serum containing 0.07 unit of insulin. The serum samples were previously dialyzed overnight against 0.9 per cent saline to reduce their glucose content.

The $\boldsymbol{\gamma}$-globulin levels of the sera were determined by paper electrophoresis using the method of Jencks, Jetton and Durrum (23). The dry paper strip patterns were evaluated by transmission densitometry. Dr. John Fahey of the National Cancer Institute kindly performed these determinations.

Binding of insulin to serum was measured according to the method of Berson and co-workers (14) based on the technique of starch block electrophoresis (24). Twotenths unit of insulin- $\mathrm{I}^{121}$ (Abbott Laboratories) was mixed with $1 \mathrm{ml}$. of serum and incubated at room temperature for 30 minutes. The insulin- $\mathrm{I}^{12}$ was dialyzed for 24 hours against distilled water prior to its use. At the end of the incubation, 1 drop of bromphenol blue solution was added and $0.2 \mathrm{ml}$. of the mixture was placed in a narrow slit in a starch block. The bromphenol blue served to mark the electrophoretic migration of albumin. The serum on the starch block was then subjected to electrophoresis for 20 hours at $4^{\circ} \mathrm{C}$. using 0.05 ionic strength barbital buffer ( $\mathrm{pH}$ 8.6) and a constant voltage of 350 volts. After the electrophoresis, the starch block was partially dried and then cut up into $1 \mathrm{~cm}$. segments, each of which was suspended in water and was centrifuged. The clear supernatant fluid was decanted, made up to $5 \mathrm{ml}$., and counted in a well-type scintillation counter. In addition to the bromphenol blue marker for serum albumin, the protein fractions were located by protein determinations according to the modified method of Folin (25). The per cent of the radioactivity which was present in the fastest moving $\gamma$-globulin region (representing bound insulin) and just behind the albumin (representing free insulin) were determined. The procedure for the measurement of the effect of serum on the binding of insulin to hemidiaphragm had been described previously (22).

The human insulin containing 1.8 units per $\mathrm{mg}$. was prepared by Dr. Frank Tietze in this laboratory. The sera samples were obtained before the morning insulin injection whenever possible. They were stored at $-20^{\circ}$ C. until the various analyses could be done. Storage for several months did not seem to have any deleterious effect on the insulin inhibitor or change the binding capacity of the sample. We are indebted to the following for samples of sera: Dr. James Moss, George- town University Medical School; Dr. E. O. Friedlander, Veterans Administration Center, Togus, Maine; Drs. James Craig and Max Miller, Western Reserve Medical School; Dr. James Wyngaarden, Duke University School of Medicine; Dr. R. K. Kiskaddon, Youngstown, Ohio; Dr. William Morgan, New York Hospital; and Dr. Reed Harwood, Boston, Mass.

\section{RESULTS}

The results of the various assays for insulin antagonist in the sera of these chronically insulinresistant patients are summarized in Table I. Although $1 \mathrm{ml}$. of serum from two of the patients (J.C. and M.W.) inhibited the effect of 0.2 unit of insulin on the rat hemidiaphragm, there was no particular correlation between the presence of antagonist and the daily insulin requirement. Since 0.07 unit of insulin was used in the fasted mouse assay, as compared to 0.2 unit in the hemidiaphragm preparation, it was possible to detect circulating insulin inhibitor in the serum of two other insulin-resistant patients (R.C. and C.J.) by the more sensitive mouse assay when no such activity was demonstrable by the hemidiaphragm method. In the serum of some patients receiving up to 2,000 units of insulin per day, no circulating antagonist was found.

Table I also indicates that the sera of all but one of the chronically insulin-resistant patients tested bound augmented amounts of insulin to the fastest moving $\gamma$-globulins. In confirmation of the results of Berson and associates (14) binding of insulin to such $\gamma$-globulins was observed only in serum from diabetic patients who had received exogenous insulin for at least three months. The per cent of insulin bound to this protein fraction varied from 0.02 to 6 per cent in seven insulinsensitive diabetics while it exceeded this amount in all of the chronically insulin-resistant patients except one (R.S.). Sera from the four cases with antagonist (J.C., M.W., R.C. and C.J.) bound more than 80 per cent of the added insulin. The amount of insulin used in these experiments, 0.2 unit per ml. of serum, is much greater than the physiologic concentration (26). There did not appear to be any -relationship between the daily insulin requirement and the amount of insulin bound. Although the sera were usually obtained before the morning insulin injections, it is possible that in patients receiving such large 
TABLE I

Summary of studies assaying serum from diabetic patients with chronic insulin resistance for insulin antagonist

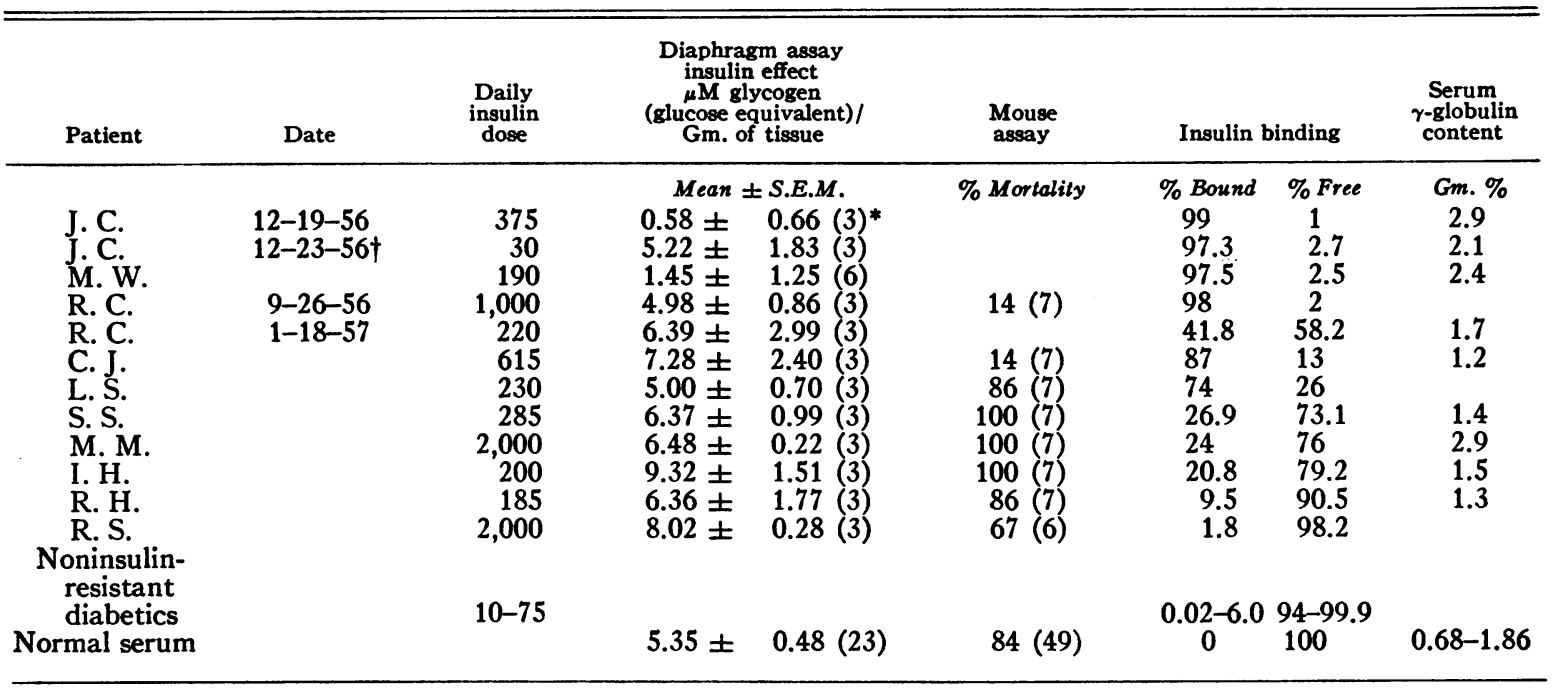

* Number of determinations.

$\dagger$ Following successful ACTH therapy.

doses of insulin a certain amount of insulin might still be present in the sera and interfere with the binding of the insulin added in vitro. Some of the insulin-resistant patients had elevated serum $\gamma$-globulin concentrations, although there was not always a direct correlation among these levels, the insulin requirement, and the ability of the serum to bind insulin.

Sera obtained from Patient J.C. over a two month period including a successful course of ACTH therapy were studied (Table II). The first sample tested, obtained on Oct. 20, 1956, when her insulin requirement was 180 units per day, did not contain insulin inhibitor by the rat hemidiaphragm assay. By Dec. 15, 1956, her

\section{TABLE II}

Serial determinations for insulin antagonist in serum from a patient $(J . C$.$) with chronic insulin resistance$

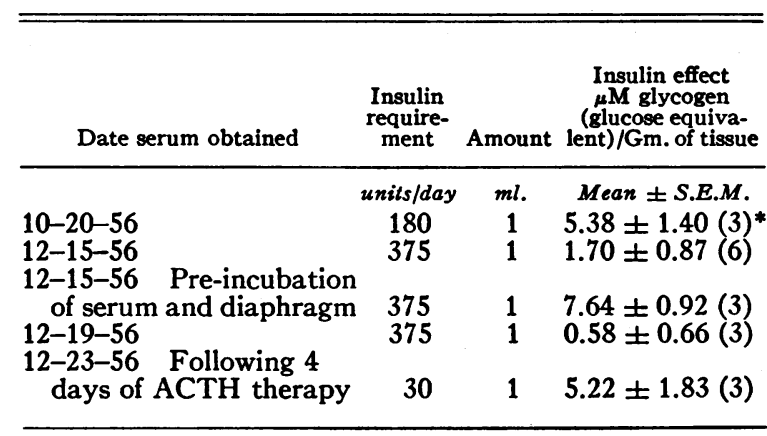

* Number of determinations. insulin requirement had increased to 375 units per day and now insulin antagonist could be detected. However, when this same serum was assayed by exposing the hemidiaphragm first to serum and then subsequently to insulin, insulin antagonist was no longer demonstrable. This observation is in agreement with the earlier results of Marsh and Haugaard (7). On Dec. 19, 1956, when insulin inhibitor was still present, ACTH administration was begun in a dosage of 60 units per day with a resultant decrease in her insulin requirement to 30 units per day on the fifth day of therapy. At this time (Dec. 23, 1956) her serum no longer inhibited insulin. Serum obtained on Dec. 19 bound 99 per cent of 0.2 unit insulin per ml. and the $\gamma$-globulins were elevated to a concentration of $2.9 \mathrm{Gm}$. per cent (Table I). Although the adrenocorticotropin therapy abolished the insulin resistance and reduced the $\gamma$ globulin level to $2.1 \mathrm{Gm}$. per cent, there was essentially no change in the binding capacity of the serum, a somewhat unexpected finding.

The ability of the insulin antagonist in chronic insulin resistance to inhibit human insulin was also demonstrated (Table III). Although there was some reduction in the amount of insulin bound to rat hemidiaphragm in the presence of serum from J.C. as compared to normal, it was not significant (Table IV). 
TABLE III

Ability of humoral insulin antagonist from patient with chronic insulin resistance to inhibit the effect of human insulin

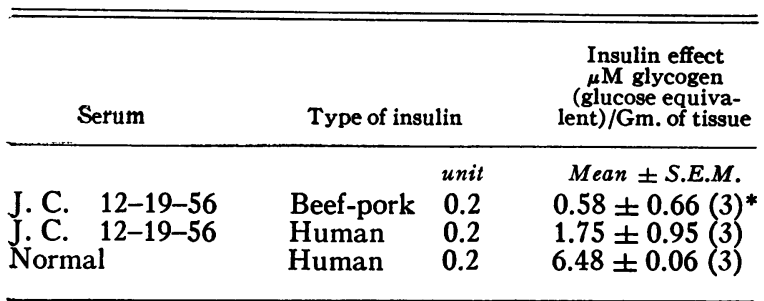

* Number of determinations.

\section{DISCUSSION}

In confirmation of previous reports $(4,5,7,8$, $10-13,18-20)$ a circulating insulin antagonist has been detected in the sera of some, but not all, patients with chronic insulin resistance. Using the fasted mouse as a more sensitive assay, it was possible to demonstrate insulin antagonist in cases where it was not detectable in the rat hemidiaphragm preparation. It is, therefore, conceivable that such antagonist could be found in the serum of most, if not all, of these patients if a sensitive enough assay were employed. In the cases where antagonist was demonstrated there was no particular correlation with daily insulin requirement. In chronic insulin resistance, an insulin antagonist, possessing many of the characteristics of an antibody, has been located in the $\gamma$-globulin fraction of the serum proteins (8-13). The finding of exalted binding of insulin to the fastest moving $\gamma$-globulins in the present cases of insulin resistance is consistent with the concept that the inhibitor is an antibody. In view of the capacity of some of these sera to bind insulin, it is not surprising that these patients were unresponsive to the usual doses of insulin. However, in the case of R.S. (Table I) there was not any definite increase in the insulin binding ability of the serum. This patient, a lipoatrophic diabetic, usually received 2,000 units of insulin per day to

TABLE IV

Effect of serum from diabetic patient with chronic insulin resistance on binding of insulin to rat hemidiaphragm

\begin{tabular}{|c|c|c|}
\hline Source of serum & $\begin{array}{c}\text { Number of } \\
\text { experiments }\end{array}$ & $\begin{array}{l}\mu \mathrm{g} \text {. insulin-I121 bound } \\
\text { per } \mathrm{Gm} \text {. of tissue }\end{array}$ \\
\hline $\begin{array}{l}\text { Normal } \\
\text { J. C. }{ }_{12-19-56}\end{array}$ & $\begin{array}{l}6 \\
6\end{array}$ & $\begin{array}{c}\text { Mean } \pm \text { S.E.M. } \\
0.018 \pm 0.0013 \\
0.012 \pm 0.0036\end{array}$ \\
\hline
\end{tabular}

control hyperglycemia and glycosuria. The fact that the use of such massive doses of insulin over a prolonged period of time did not produce augmented insulin binding capacity is contrary to the idea that increased insulin binding by serum is secondary to the administration of large amounts of insulin. This patient's serum has also been studied by Arquilla and Stavitsky using an immunologic technique based on hemolysis of sensitized red cells (27). These investigators found that although there were antibodies to insulin, they were not present in very high titer. It therefore appears that the insulin resistance observed in lipoatrophic diabetes is of some other origin (28).

The successful treatment of insulin resistance with adrenocorticotropin has been reported (12, 18, 19). However, ACTH therapy has not been beneficial in all cases of chronic insulin resistance, even though a circulating insulin inhibitor has been detected $(10,20)$. It has also been demonstrated that serum obtained after such therapy no longer inhibited insulin (7). Similar observations were made on Patient J.C. whose insulin resistance was successfully treated with ACTH. During the period when insulin antagonism was demonstrable, $1 \mathrm{ml}$. of her serum bound 99 per cent of 0.2 unit of insulin. Even after therapy with ACTH, when insulin inhibitor was no longer detected, her serum was still able to bind 97.3 per cent of this amount of insulin. This finding was somewhat unexpected since it was believed that the insulin resistance resulted from the increased insulin binding protein. With the disappearance of clinical insulin resistance, the anticipated reduction in insulin binding was not observed. During ACTH therapy, her serum was capable of binding at least 200 units of insulin per L., yet her daily insulin requirement was only 30 units. This discrepancy could be explained in two possible ways. Although the insulin binding capacity of the serum was virtually unchanged, under the influence of ACTH the insulin-insulin binding protein complex might now be physiologically active. Another possible explanation depends on the findings of Berson and Yalow that there are two rates of dissociation of the insulininsulin binding protein complex (16). If the $\mathrm{ACTH}$ causes a more rapid dissociation of insulin from the insulin binding protein, then it is possible that less insulin would be required for con- 
trol of the diabetes even though the actual amount of the insulin binding protein remains the same. It is not possible to conclude from the present information which of these two possibilities is correct. It has also been suggested that a sudden decrease in insulin requirement could follow a period of therapy using large amounts of insulin as a result of an accumulation of high concentrations of bound insulin in the serum (29). It is unlikely that this, rather than $\mathrm{ACTH}$, was responsible for the reduction in insulin requirement of Patient J.C. since her insulin requirement had been gradually increasing up to 375 units per day for a period of two months before ACTH therapy. In addition, even after the ACTH therapy was discontinued, she continued to require only 30 units of insulin daily for several weeks. Then her insulin requirement again began to increase so that steroid therapy was reinstituted.

Lowell reported that the circulating insulin antagonist in his patient with chronic insulin resistance did not protect mice from the hypoglycemic effects of human insulin (30). Furthermore, when human insulin was administered to this patient, there was no evidence of insulin resistance. From these studies he concluded that there was no cross-reaction between human insulin and the antibody resulting from beef or pork insulin. Similar conclusions were obtained by Burrows, Peters and Lowell, who found that human insulin did not displace beef-pork insulin from the insulin binding protein (17). However, using an immunologic technique, Arquilla and Stavitsky did find cross-reaction between human insulin and antibodies prepared using beef or pork insulin (31). The insulin inhibitor in the serum of J.C. antagonized the effect of human insulin just as effectively as beef-pork insulin. The reason for this discrepancy is not apparent at this time, but it is possible that in the preparation of the human insulin used in our experiments, it was modified in some way so that it is different from native human insulin and less species specific. It is of some importance to establish definitely whether native human insulin does react with this insulin binding protein in order to assess its role, if any, as an etiologic factor in some cases of diabetes. At present, it seems unlikely that it is of etiologic importance since insulin binding is not apparent until exogenous insulin has been administered for about three months (14).

Although in the present studies protein fractionation was not done to localize the insulin antagonist, it seems likely from other similar cases that the material was an antibody to insulin (4, $5,7,8-13)$. This antibody, present in cases of chronic insulin resistance, resides in the $\gamma$-globulins and is different from the $\alpha_{1}$-globulin fraction which we have described in the insulin resistance associated with diabetic acidosis $(21,22)$. The antagonist in diabetic acidosis is still capable of inhibiting insulin in the hemidiaphragm assay even though it is preincubated with the diaphragm and the insulin subsequently added. As shown in Table II this is not true of the insulin antagonist present during chronic insulin resistance. The $\alpha_{1}$-globulin antagonist has been demonstrated in sera from patients who have never had previous insulin therapy while the insulin binding protein has never been found in this situation. Furthermore, the insulin resistance associated with diabetic acidosis is transient compared with that in chronic insulin resistance.

\section{SUMMARY}

Serum from 2 of 10 cases of chronic insulin resistance was capable of inhibiting the effect of 0.2 unit of insulin in the rat hemidiaphragm assay. Using a more sensitive system, the fasted mouse, it was possible to detect insulin antagonist in 2 other cases where it could not be demonstrated with the hemidiaphragm preparation. In 9 of the 10 cases studied there was an increased binding of insulin to insulin binding protein as compared to insulin-sensitive diabetic patients. In some cases this $\gamma$-globulin binding amounted to over 90 per cent of 0.2 unit of insulin per ml. of serum. In general there was good correlation between the amount of insulin binding and the demonstration of circulating insulin antagonist. Although the total serum $\gamma$-globulin level was elevated in some cases, there was no particular relationship among these values, the daily insulin requirement, or the amount of insulin bound. In one patient, treatment with adrenocorticotropin (ACTH) abolished the insulin resistance, and insulin antagonist, previously present, was no longer demonstrable. Contrary to expectations this therapy did not diminish the ability of the serum to bind large 
amounts of insulin. The insulin antagonist also inhibited human insulin.

In contrast to the insulin antagonist associated with diabetic acidosis, the inhibitor in cases of chronic insulin resistance is not effective unless the hemidiaphragm, insulin, and serum are all incubated simultaneously.

\section{REFERENCES}

1. Martin, W. P., Martin, H. E., Lyster, R. W., and Strouse, S. Insulin resistance; critical survey of the literature with report of a case. J. clin. Endocr. 1941, 1, 387.

2. Axelrod, A. R., Lobe, S., Orten, J. M., and Myers, G. B. Insulin resistance. Ann. intern. Med. 1947, 27, 555.

3. Smelo, L. S. Insulin resistance. Proc. Amer. Diab. Ass. 1948, 8, 77.

4. Glen, A., and Eaton, J. C. Insulin antagonism. Quart. J. Med., 1938, 7, 271.

5. Lowell, F. C. Immunologic studies in insulin resistance. II. The presence of a neutralizing factor in the blood exhibiting some characteristics of an antibody. J. clin. Invest. 1944, 23, 233.

6. Lerman, J. Insulin resistance: The role of immunity in its production. Amer. J. med. Sci. 1944, 207, 354.

7. Marsh, J. B., and Haugaard, N. The effect of serum from insulin-resistant cases on the combination of insulin with the rat diaphragm. J. clin. Invest. 1952, 31, 107.

8. DeFilippis, V., and Iannaccone, A. Insulin-neutralizing activity of gamma-globulins derived from the serum of an insulin-resistant patient. Lancet 1952, $1,1192$.

9. Dituri, B. Insulin-resistant diabetes after total pancreatectomy; report of case. New Engl. J. Med. 1954, 251, 13.

10. Kaye, M., McGarry, E., and Rosenfeld, I. Acquired insulin resistance: A case report. Diabetes 1955, 4, 133

11. Sehon, A. H., Kaye, M., McGarry, E., and Rose, B. Localization of an insulin neutralizing factor by zone electrophoresis in a serum of an insulin-resistant patient. J. Lab. clin. Med. 1955, 45, 765.

12. Yankelowitch, T., Massry, S., and Gitter, S. Insulin resistant diabetes with insulin antibodies. A case report. Diabetes 1956, 5, 457.

13. Colwell, A. R., and Weiger, R. W. Inhibition of insulin action by serum gamma globulin. J. Lab. clin. Med. 1956, 47, 844.

14. Berson, S. A., Yalow, R. S., Bauman, A., Rothschild, M. A., and Newerly, K. Insulin- ${ }^{12}$ metabolism in human subjects: Demonstration of insulin binding globulin in the circulation of insulin treated subjects. J. clin. Invest. 1956, 35, 170.

15. Welsh, G. W., Henley, E. D., Williams, R. H., and Elgee, N. J. The distribution and degradation of
$I^{181}$-labeled insulin in normal subjects and in diabetics (abstract). J, clin. Endocr. 1955, 15, 861.

16. Berson, S. A., and Yalow, R. S. Kinetics of reaction between insulin and insulin-binding antibody (abstract). J. clin. Invest. 1957, 36, 873.

17. Burrows, B. A., Peters, T., and Lowell, F. C. Physical binding of insulin by gamma globulins of insulin-resistant subjects. J. clin. Invest. 1957, 36, 393.

18. Howard, J. E: Discussion of Margen, S., Michaels, G. D., Boling, L. A., and Kinsell, L. W. Hormonal regulation of fat metabolism. II. Effects of ACTH and certain steroid hormones upon the utilization of infused acetoacetate and octonic acid in Proceedings of the Second Clinical ACTH Conference, J. R. Mote, Ed. New York, Blakiston, 1951, vol. 1, p. 318.

19. Kleeberg, J., Diengott, D., and Gottfried, J. A case of insulin resistance treated with corticotropin. J. clin. Endocr. 1956, 16, 680.

20. Loveless, M. H., and Cann, J. R. Distribution of "blocking" antibody in human serum proteins fractionated by electrophoresis-convection. J. Immunol. 1955, 74, 329.

21. Field, J. B., and Stetten, D., Jr. Humoral insulin antagonism associated with diabetic acidosis. Amer. J. Med. 1956, 21, 339.

22. Field, J. B., and Stetten, D., Jr. Studies on humoral insulin antagonists in diabetic acidosis. Diabetes 1956, 5, 391.

23. Jencks, W., Jetton, M. R., and Durrum, E. L. Paper electrophoresis as a quantitative method. Biochem. J. 1955, 60, 205.

24. Kunkel, H. G., and Slater, R. J. Zone electrophoresis in a starch supporting medium. Proc. Soc. exp. Biol. (N. Y.) 1952, 80, 42.

25. Lowry, O. H., Rosebrough, N. J., Farr, A. L., and Randall, R. J. Protein measurement with the Folin phenol reagent. J. biol. Chem. 1951, 193, 265.

26. Vallance-Owen, J., and Hurlock, B. Estimation of plasma-insulin by the rat diaphragm method. Lancet 1954, 1, 68.

27. Arquilla, E. R., and Stavitsky, A. B. The production and identification of antibodies to insulin and their use in assaying insulin. J. clin. Invest. 1956, $35,458$.

28. Lawrence, R. D. Lipodystrophy and hepatomegaly with diabetes, lipaemia and other metabolic disturbances. Lancet 1946, 1, 724.

29. Berson, S. A., and Yalow, R. S. Studies with insulin-binding antibody. Diabetes 1957, 6, 402.

30. Lowell, F. C. Immunologic studies in insulin resistance. I. Report of a case exhibiting variations in resistance and allergy to insulin. J. clin. Invest. 1944, 23, 225.

31. Arquilla, E. R., and Stavitsky, A. B. Evidence for the insulin-directed specificity of rabbit anti-insulin serum. J. clin. Invest. 1956, 35, 467. 